\title{
Characteristics of Summer Precipitation around the Western Ghats and the Myanmar West Coast
}

\author{
Dibas Shrestha, ${ }^{1,2}$ Rashila Deshar, ${ }^{2,3}$ and Kenji Nakamura ${ }^{4}$ \\ ${ }^{1}$ Nepal Academy of Science and Technology, Khumaltar, Lalitpur 3323, Nepal \\ ${ }^{2}$ Kathmandu Institute of Applied Sciences, Banasthali 15, Kathmandu 23002, Nepal \\ ${ }^{3}$ Central Department of Environmental Science, Tribhuvan University, Kirtipur, Kathmandu 44618, Nepal \\ ${ }^{4}$ Department of Economics on Sustainability, Dokkyo University, 1-1 Gakuen-cho, Soka-shi, Saitama 340-0042, Japan \\ Correspondence should be addressed to Dibas Shrestha; st.dibas@yahoo.com
}

Received 31 July 2014; Revised 31 December 2014; Accepted 10 February 2015

Academic Editor: Chung-Lin Shie

Copyright (C) 2015 Dibas Shrestha et al. This is an open access article distributed under the Creative Commons Attribution License, which permits unrestricted use, distribution, and reproduction in any medium, provided the original work is properly cited.

\begin{abstract}
Characteristics of summer (June-August) precipitation over two coastal mountain regions in South Asia (Western Ghats: WG and Myanmar West Coast: MWC) with a focus on topographic impact are analyzed using the 13-year (1998-2010) high spatial resolution $\left(0.05^{\circ} \times 0.05^{\circ}\right)$ version 6 data obtained from the Tropical Rainfall Measuring Mission (TRMM) Precipitation Radar (PR). A relationship between precipitation patterns and topography was observed in the coastal mountains. In both the WG and MWC, maximum rainfall along a tight line on the upwind side of the coastal mountains is primarily attributed to rain frequency. However, intense precipitation was observed over the offshore regions. Compared with the WG, deeper and large-scale precipitation systems develop over the MWC, producing more intense rainfall. It is suggested that insufficient humidity deters large-scale convection over the WG, and the atmosphere is sufficiently moist over the MWC.
\end{abstract}

\section{Introduction}

The atmospheric response to orography is one of the most influential factors affecting the spatial and temporal distribution of precipitation around mountainous areas, because mountains alter the flow of air and respond to solar radiation differently than the surrounding atmosphere [1]. As a consequence, precipitation in mountainous environments is higher in some regions and lower in others. An important characteristic of precipitation in mountainous areas is its relation to the elevation. Total precipitation generally increases with elevation up to a certain height and then begins to decrease on a mountain's upwind sides [2]. The study of spatial patterns of precipitation over mountains is critically important for a range of applications. For instance, landslides are triggered by intense and/or persistent precipitation at particular locations within mountainous terrain $[3,4]$. In addition, such studies are important for water-resource and flood-control management, design and planning of various engineering projects [5], and better understanding of land surface-atmosphere interactions [6-8].
In general, rainfall over the mountainous areas is associated with orographic lifting as the low-level flow passes or the terrain. One mechanism consists of rising air that cools adiabatically, releasing moisture as precipitation on the windward side of the mountain. On the other side of the mountain, the air descends and warms, drying as precipitation dissipates. This implies that underlying mechanisms play an important role in organizing precipitation systems in mountainous regions. However, measurements utilizing existing gauge networks and ground based remote-sensing techniques are not adequate to fully understand these mechanisms [9, $10]$.

The Precipitation Radar (PR) onboard the Tropical Rainfall Measuring Mission (TRMM) satellite revolutionized the global view of the distribution and mechanisms of precipitation by providing high spatial resolution precipitation measurements as well as profiles of the vertical structure. Despite a lack of high temporal resolution, this instrument revealedfor the first time-spatially robust patterns of precipitation distributions in mountainous areas [7, 11-14]. 
Striking spatial gradients in the climatology of precipitation, on the scales of tens of kilometers, were reported for the Himalayas [6, 7, 15-18], Andes [10, 11, 19], Olympic Mountains [1], Alps [20], and South Asian coastal mountains $[12,21-23]$. Although several studies have shown that the volume of rainfall generally increases with altitude up to a certain height on windward sides, there is still a lack of clarity about a responsible factor (rain frequency or intensity) that determines the rainfall maxima over higher-elevation areas. Some studies [5, 24-26], utilizing observational data and numerical simulation, found that greater quantities of rainfall recorded at higher altitudes could be attributed to greater duration and higher frequency of precipitation.

This investigation is related to a previous TRMM-based study by Shrestha et al. [17]. On the basis of 11-year (19982008) TRMM PR 2A25 near-surface rainfall data, Shrestha et al. [17] studied precipitation characteristics in the central Himalaya for the premonsoon and monsoon seasons, focusing on the rainfall-elevation relationship. Shrestha et al. noticed that topography had a strong bimodal impact on the characteristics of the precipitation distribution during the summer monsoon: a large amount of rainfall in the higher Himalayas occurs as a result of frequent rainfall while rainfall maxima upstream of the mountain terrain is primarily associated with intense precipitation. The study further suggested that rainfall maxima over low-altitude areas are caused by convection that occurs when low-level, warm, moist airflow encounters the mountain foothills, and the precipitation occurs over the higher terrain because of forced lifting. This phenomenon was observed in the most-rugged portion of the Himalayas where three nearly parallel mountains stretch from east to west. The question arises as to whether this mechanism would hold over other major mountain ranges around the world.

The mountainous western coasts of India and Myanmar are the heaviest precipitation areas in south Asia during the monsoon period. In these areas, narrow mountain ranges are an important organizing agent anchoring intense monsoon precipitation on their windward sides. The location and intensity of these two precipitation maxima are a result of the interaction between the northward propagating monsoon intraseasonal oscillation and the shallow orography in both the Myanmar West Coast (MWC) and Western Ghats (WG). Though both regions receive heavy rainfall during the monsoon, there is a significant difference in their rainfall characteristics. In the MWC, low to moderate rain dominates to the total rain whereas heavy rain dominates more in the WG [21]. Kumar et al. [21] suggested that the differences are due to moisture availability, updraft, amount, and characteristics of cloud condensate in the two regions.

This study examines the precipitation characteristics over the coastal mountains of south Asia (Figure 1). The coastal mountainous regions include the WG and MWC. The main objective of this study is to understand the impact of coastal mountains on the rainfall distributions and the differences in their rainfall mechanisms in these two regions. For this purpose, near-surface rain rate, rain frequency, conditional rain rate, rain type, and vertical rain structure are investigated.

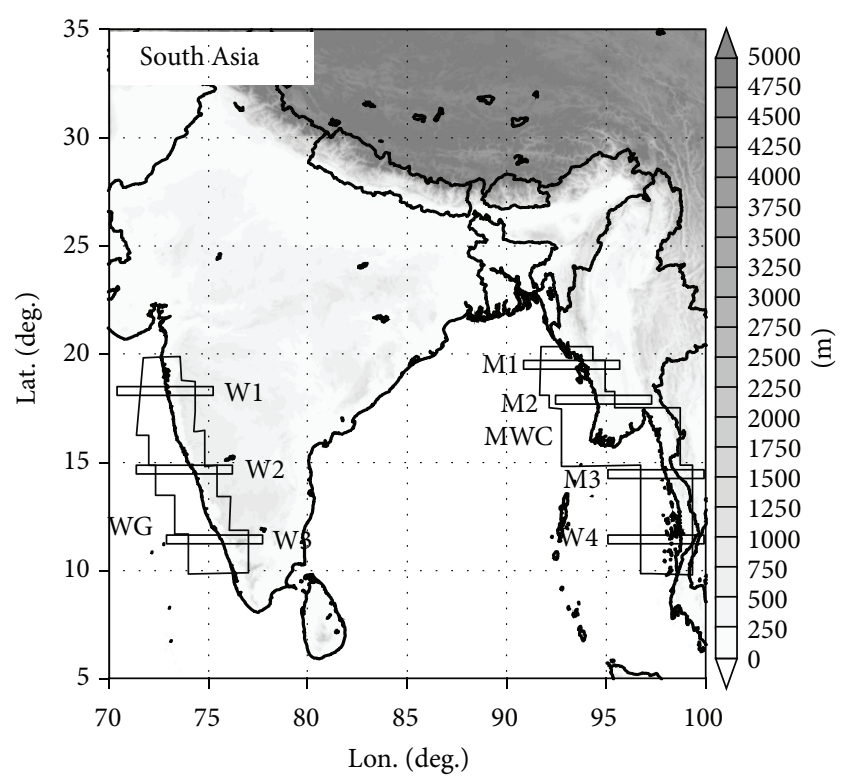

FIGURE 1: Topography of the region of interest and subregions: Western Ghats (WG); Myanmar West Coast (MWC) (area bounded by the bold black line). Black polygons indicate the location of 7 swath profiles running from west to east, of which an example from each subregion is shown in Figure 3.

\section{Data and Methodology}

2.1. TRMM/PR. Tropical Rainfall Measuring Mission (TRMM) is a joint mission between the United States National Aeronautics and Space Administration (NASA) and Japan Aerospace Exploration Agency (JAXA) launched in November, 1997. TRMM is specifically dedicated to monitoring rainfall in the tropics and subtropics (extending from $36^{\circ} \mathrm{S}$ to $36^{\circ} \mathrm{N}$ ). TRMM includes the first space-born PR, a passive microwave imager (TMI), visible infrared scanner (VIRS), lightning imaging sensor (LIS), and clouds and earth's radiant energy system (CERES). The first three instruments are designed to obtain rainfall and other relevant information (e.g., rain type, echo-top height, and cloud type), individually.

The PR is a core sensor onboard the TRMM satellite, designed to provide a three-dimensional view of storms [27, 28]. PR has a horizontal resolution of $\sim 4 \times 6 \mathrm{~km}$, and vertical resolution of $250 \mathrm{~m}$ at nadir with a $215 \mathrm{~km}$ swath width. The frequency of the $\mathrm{PR}$ is $13.8 \mathrm{GHz}$. The $\mathrm{PR}$ is able to detect reflectivities down to approximately $17 \mathrm{dBZ}$, equivalent to fairly light rain rates of $\sim 0.5 \mathrm{~mm} / \mathrm{h}$. The pixel size, swath width, and sensitivity to rain changed ( $5 \mathrm{~km}$ pixel size, $247 \mathrm{~km}$ swath width, and sensitivity reduced by $1.2 \mathrm{~dB}$ ) after an orbit boost from $350 \mathrm{~km}$ to $402.5 \mathrm{~km}$ in 2001 . However, these differences are insignificant and are neglected for the moderate and heavy rain, which are focused in this study.

In general, there are certain sources of error in the temporal average of TRMM PR-estimated rainfall, that is, retrieval and sampling errors [6]. The former includes error in the remote-sensing methods, and the latter is related to the poor temporal resolution. Sampling error depends primarily on sampling frequency. The sampling of TRMM satellite 
over the study area is limited to 1-2 snapshots per day [29]. Therefore, the sampling error is likely to be more significant than measurement error [30]. The effect of these errors will be sufficiently low in long-period data. A recent study by Nesbitt and Anders [10] showed that current climatology is sufficient to resolve statistically significant precipitation patterns in regions with large precipitation totals including the Himalayas, WG, and MWC.

The primary rainfall data set used here was the nearsurface rain obtained from the TRMM/PR 2A25 Version 6 (V6) [31] for thirteen (1998-2010) summer monsoon (JuneAugust). "Near-surface" rainfall is defined as the range bin closest to the surface that is generally free from groundclutter contamination. The vertical height of the near-surface ranges from $500 \mathrm{~m}$ above ground level (AGL) at nadir to $2000 \mathrm{~m}$ AGL at the edge of the observation swath. The mean rain rate is a product of conditional rain rate (near-surface rain rate only when it is raining) and rain frequency (number of rain samples divided by total number of samples). Another TRMM/PR product (2A23) was used for analyzing the storm height. The PR $2 \mathrm{~A} 23$ storm height is based on the $18 \mathrm{dBZ}$ (equivalent to approximately $0.5 \mathrm{~mm} / \mathrm{h}$ ) echo-top height. Storm height was calculated only when rain was detected at the near-surface. One of the limitations was that the study did not use latest TRMM PR Version 7 (V7) data that was released a year before as a replacement for V6. This new version is considered superior over land areas compared to the previous versions because of changes to the vertical profile of hydrometeor characteristics, which affects the reflectivityto-rainfall rate $(Z-R)$ relationship and attenuation correction.

Rain-type characteristics were investigated using the PR product $2 \mathrm{~A} 25$ which is the same as the $2 \mathrm{~A} 23$ rain-type field. The PR algorithm classifies precipitation into three categories: convective, stratiform, and other, considering the vertical and horizontal distribution of reflectivity [32]. The $V$-method is based on detection of the bright band and intensity of the radar echo. The $H$-method, originally based on Steiner et al. [33], uses the horizontal pattern of radar reflectivity for each profile.

For data processing, data were first binned from each individual swath onto a regular grid with spacing of $0.05^{\circ}$ (approximately $5 \times 5 \mathrm{~km}$ ). The gridded data were than averaged over the entire period of record to produce a daily mean climatology.

2.2. Reanalysis Data. The Japanese 25 -year Reanalysis (JRA25) datasets produced by Japan Meteorological Agency (JMA) and Central Research Institute of Electric Power Industry (CRIEPI) were used to examine the synoptic conditions. The datasets are global in coverage, with $2.5^{\circ}$ and $1.25^{\circ}$ spatial resolution and $6 \mathrm{~h}$ temporal resolution. In this study, monthly mean climatological normal values for 1981-2010 with a spatial resolution of $1.25^{\circ}$ were calculated for summer seasons.

2.3. Topographic Data. The Global 30 Arc-Second Elevation Data Set (GTOPO30) is regridded at $0.05^{\circ}$ resolution from approximately $1 \mathrm{~km}$, global raster Digital Elevation Model
(DEM) data developed by the Earth Resources Observation Systems (EROS) Data Center of the United States Geological Survey (USGS). GTOPO30 was derived from several raster and vector sources of topographic information.

\section{Results}

3.1. Horizontal Patterns of Rainfall. The west coasts of India and Myanmar receive the heaviest precipitation of the south Asian summer monsoon (June-August) [22, 34]. In both the WG and MWC regions, the maximum rainfall zone forms along a tight line on the windward side of the coastal mountains (Figure 2(a)), as previously reported [12, 21, 35]. Rainfall primarily occurs along the windward side of the coastal mountains and propagates in an offshore direction. This finding is in contrast to the previous investigation using coarseresolution datasets, which indicated an offshore precipitation maximum in the WG region [36]. In addition, by utilizing TRMM PR data at $0.5^{\circ}$ resolution, Xie et al. [22] noted that the location of maximum rainfall was displaced from the mountain slopes by approximately $50 \mathrm{~km}$. At the fine resolution in this study, it is apparent that the rainfall maximum is not displaced from the mountain slopes [35]. Although similar features of rainfall patterns are observed over both regions, the MWC region shows a wide area of maximum rainfall (Figure 2(a)). A typical feature is observed in the WG region, where maximum rainfall occurs around $500 \mathrm{~m}$ above mean sea level (AMSL) along the entire mountain range (Figure 2(a)). Interestingly, the amount of rainfall over the Deccan Plateau to the east of the WG, the downwind side of the Myanmar Mountains and the Irrawaddy River Basin is insignificant despite the fact that the WG and MWC mountains are not very high. This is accounted by the classic rainshadow effect of the corresponding mountain ranges [37].

The patterns of rain frequency were generally similar to the distribution of rain rate in both regions, with a larger and more homogeneous width of the coastal maxima (Figure 2(b)). The most frequent precipitation, by far, was seen over the MWC regions. Although the western coast of Myanmar is a region of steep orography, the large spatial extent of higher rain frequency suggests there are effects other than just orographic enhancement [35]. Numerical simulation by Xie et al. [22] showed that mesoscale heating interacts with the large-scale circulation to force broader rainfall maxima over the Bay of Bengal. In contrast to rain frequency, intense rainfall $(>4 \mathrm{~mm} / \mathrm{h}$ ) was primarily observed offshore (Figure 2(c)). The conditional rain rate was higher over the MWC compared with the WG. This is consistent with the distribution of mean conditional reflectivity at the surface shown by Biasutti et al. [35].

Figure 2(d) illustrates the horizontal distribution of storm-top height over the study areas during summer monsoon. The actual storm heights presented here are the height of the top of the precipitation column above ground level rather than MSL. Interestingly, higher storm-tops appear over a broader area of open ocean from the western coast of Myanmar into the eastern Bay of Bengal. This feature is associated with the convective nature of the monsoon. 

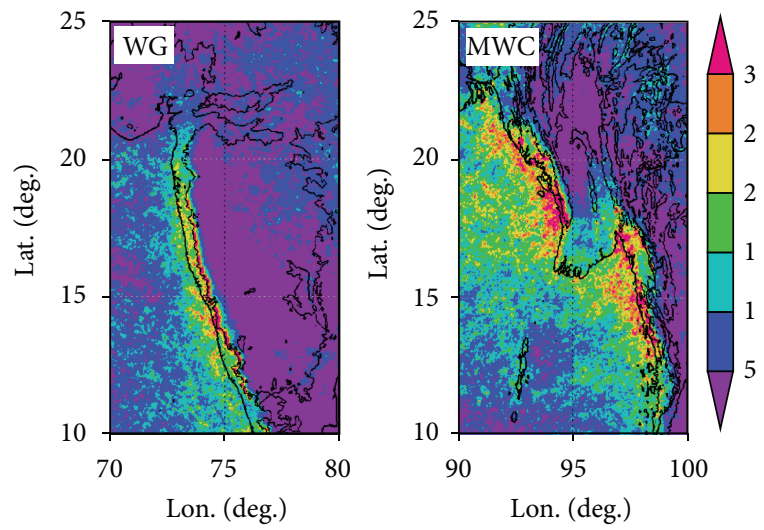

(a) Rain rate $(\mathrm{mm} / \mathrm{d})$
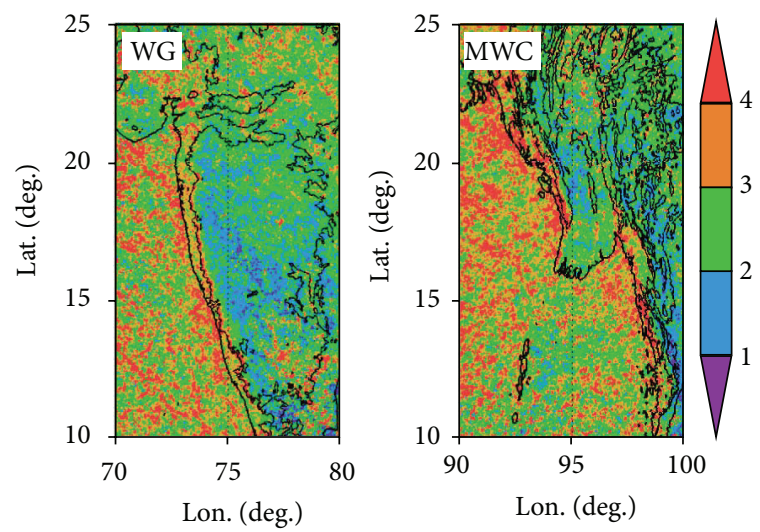

(c) Conditional rain rate $(\mathrm{mm} / \mathrm{h})$
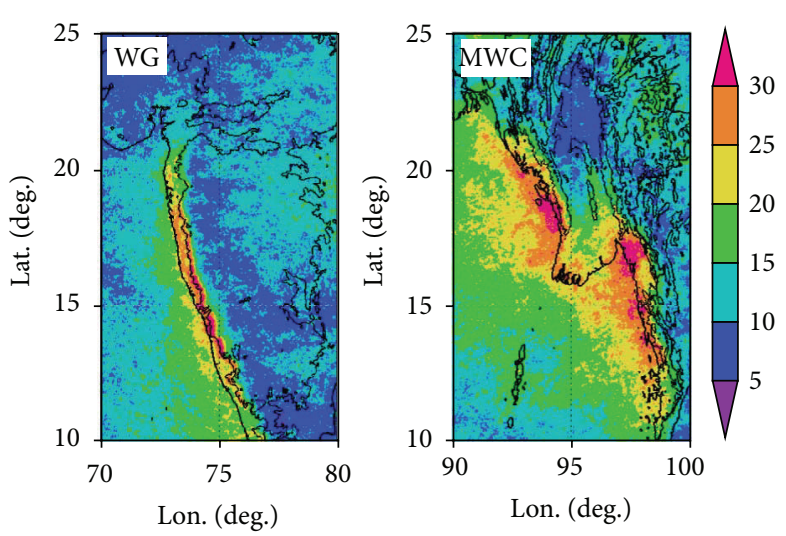

(b) Rain frequency (\%)
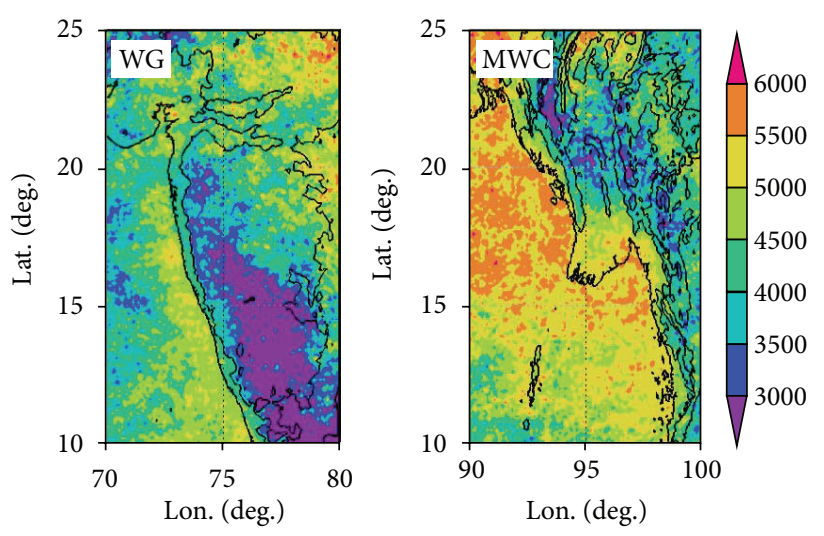

(d) Storm-top height (m)

FIGURE 2: Horizontal distributions of summer (June-August) rainfall characteristics in the 13-year period (1998-2010) for the Western Ghats (WG, left panel of each figure) and Myanmar West Coast (MWC, right panel of each figure) region: (a) rain rate, (b) rain frequency, (c) conditional rain rate, and (d) storm height. Contour line represents $500 \mathrm{~m}$ elevations.

Further, this is consistent with the greater probability of wide convective cores and a broad stratiform region in the Bay of Bengal as shown by Romatschke and Houze Jr. [12]. Note that the taller storms were observed only over the coastal oceans in both study regions, suggesting that intense rainfall offshore is due to deeper precipitation systems. Over the coastal mountainous region storms are generally shallower than those over the adjacent ocean. This tendency is similar to that of taller storms over the Gangatic plains and shallower storms over the higher Himalayas [17]. Although the conditional rain rate is higher in the coastal mountains, storm-top height is significantly lower. This is probably related to weak convection.

Evaluating rainfall characteristics along swath profiles is advantageous for investigating precipitation distributions in response to topography. Seven swath profiles, three from WG (W1, W2, and W3) and four from MWC (M1, M2, M3, and M4), roughly perpendicular to the respective coastal mountains were selected (Figure 1). These swath locations were selected on the basis of smooth and continuous patterns of rain characteristics across the WG and MWC. Each swath profile is approximately $50 \mathrm{~km}$ wide $\times 500 \mathrm{~km}$ long. Rain characteristics (daily rain total, conditional rain rate, and frequency) and elevation along one profile represent the average over the width of the profile. All seven profiles illustrate the orographic effect of the coastal mountains, although there are noticeable differences in peak locations between the WG and MWC (Figures 3(a) and 3(b)). Over the WG regions, two distinct rainfall peaks appear in all swath profiles. The first peak is located a few $\mathrm{km}$ off the western coast of India, while the second major peak appears near the top of the mountain ranges. Offshore peaks are generally associated with higher conditional rain rates, while mountain rain peaks are primarily attributed to rain frequency. This feature is consistent with the precipitation distribution in the central Himalayas, where an intensity-dominated, low-altitude rainfall peak and a frequency-dominated, higher-altitude peak were identified by Shrestha et al. [17]. Similarly, the MWC region also illustrates the maximum rainfall occurring near the top of the mountains, but the rain frequency does not correlate well to the maximum rainfall zone. In contrast, a broad rain frequency peak extends outward from the windward mountain slopes to hundreds of km offshore in the MWC region.

Analysis of the storm-type distribution is more important over inhomogeneous regions, because it is directly related to precipitation mechanisms. The spatial patterns of stratiform and convective rain are generally similar in both regions 


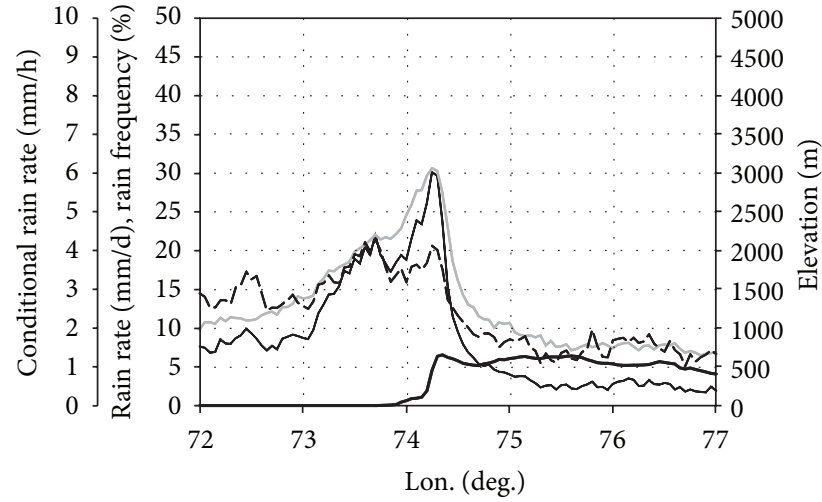

(a) $\mathrm{W} 2(15 \mathrm{~N}-15.5 \mathrm{~N})$

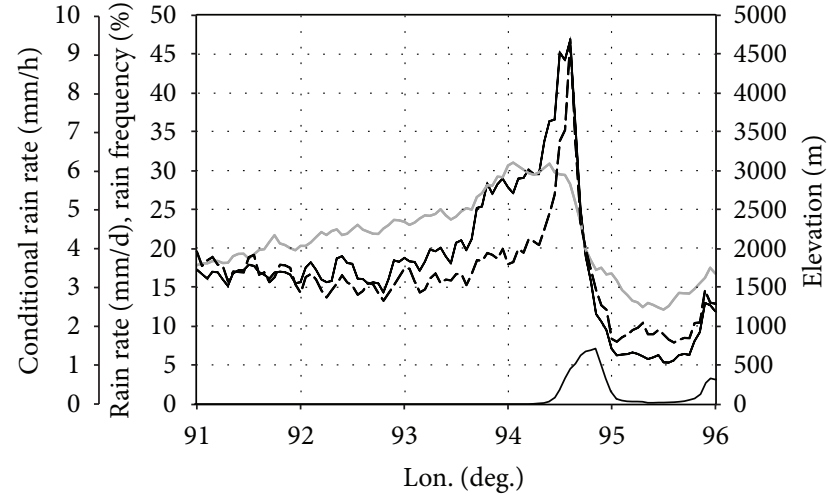

(b) $\mathrm{M} 2(18 \mathrm{~N}-18.5 \mathrm{~N})$

FIGURE 3: Rainfall characteristics (rainfall, conditional rain rate, and rain frequency) across the (a) WG and (b) MWC regions. Heavy solid, thin solid, gray, and dashed lines represent topography $(\mathrm{m})$, daily rainfall total $(\mathrm{mm} / \mathrm{d})$, rain frequency $(\%)$, and conditional rain rate $(\mathrm{mm} / \mathrm{h})$, respectively. See Figure 1 for location.
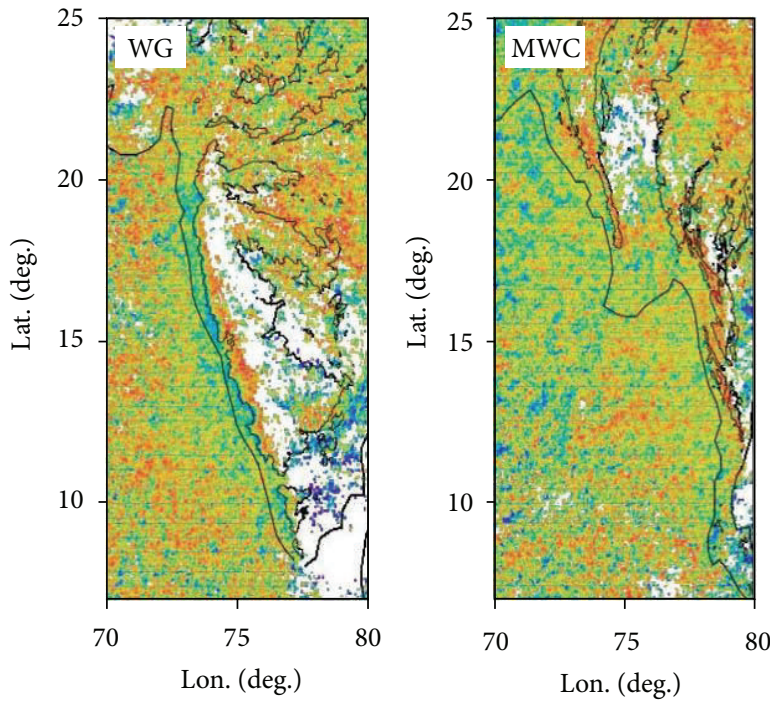

(a) Stratiform rain percentage
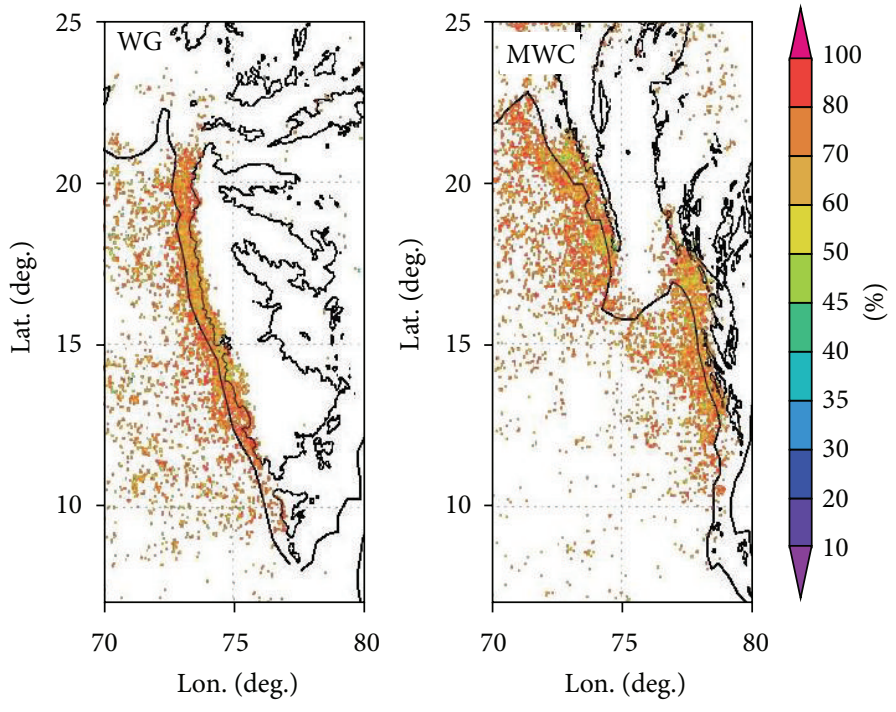

(b) Convective rain percentage

FIGURE 4: Spatial patterns of stratiform (a) and convective (b) percentage of the WG (left panel of each figure) and MWC (right panel of each figure). Pixels where the total precipitation is $<0.15 \mathrm{~mm} / \mathrm{h}$ are deleted from these and all the following percentage plots. Orographic contours are as in Figure 2.

(Figure not shown). Figure 4 shows the contribution of stratiform and convective rain to the total amount. Over the both regions, convective rain dominates (above 50\%) the total precipitation amount, while stratiform contributes less than 50\%. Romatschke and Houze Jr. [12] also observed similar stratiform and convective rain distribution. A distinct feature was detected over the WG, where stratiform rain fraction is much less in the low-altitude areas (below $500 \mathrm{~m}$ contour line), which suggests that a large fraction of rain comes from convective systems. This feature is consistent with the findings of Romatschke and Houze Jr. [12], who showed that the WG is an exceptional area where precipitation systems are mostly convective. Over the MWC, stratiform and convective precipitation make almost equal contributions to the total rainfall. The tendency of precipitation maxima to occur where large stratiform regions are formed in association with extreme convection has been noted previously [12]. For a more detailed understanding of the storm-type distribution, frequency and conditional rain rates are investigated for both stratiform and convective rain (Figure 5). Stratiform rain is most frequent in the MWC region (Figure 5(a)), whereas convective rain is most frequent in the WG (Figure 5(b)). Although a higher frequency of convective rain appears along a certain height of the WG, there is intense convective rain 


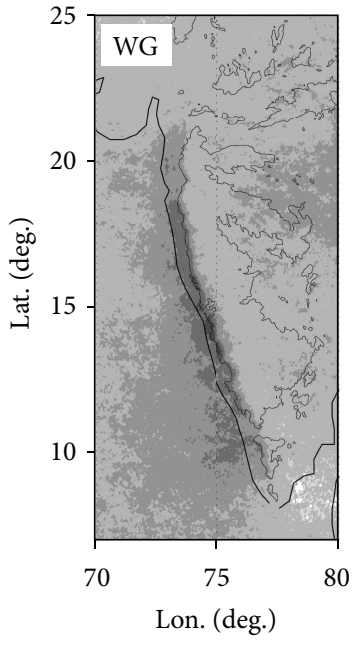

(a) Stratiform rain frequency (\%)

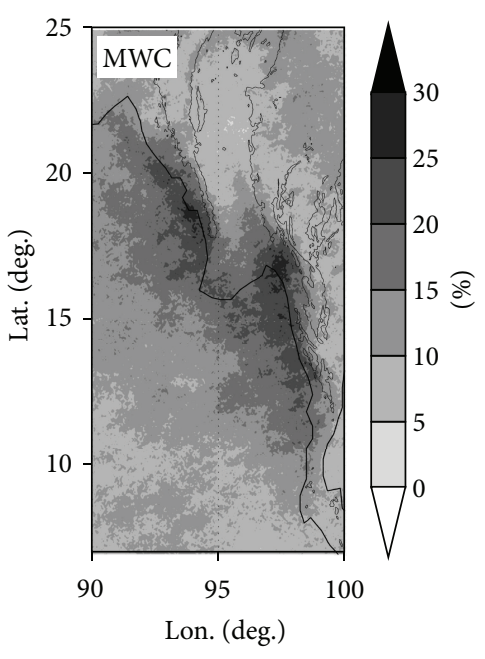

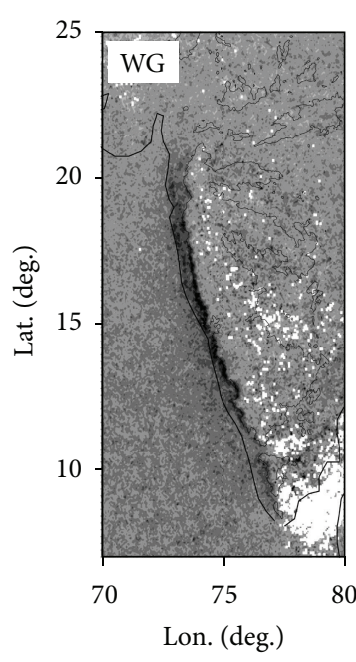

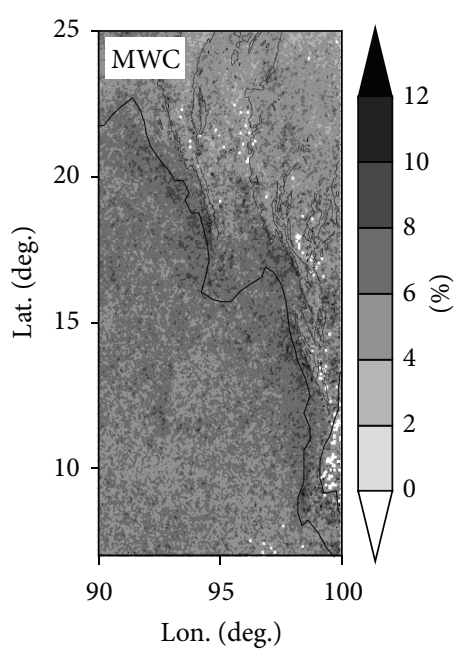

(b) Convective rain frequency $(\%)$

FIGURE 5: Distributions of rainfall characteristics over the WG (left panels) and MWC (right panels) regions: (a) stratiform rain frequency, (b) convective rain frequency. Rain frequency here is defined as ratio of number of rain samples to number of total samples expressed in percentage. Total sample includes stratiform, convective, other, and no rain. Orographic contours are as in Figure 2.

along the coastline of the western coastal region of India (Figure not shown). This difference in the location of the maximum rain frequency and conditional rain rate of convective rain suggests that maximum precipitation over the WG is primarily attributed to frequent, but relatively weak, convection. In contrast, much more intense convective rain $(>8 \mathrm{~mm} / \mathrm{h})$ is observed over a broader area of the MWC region, including the coastal mountains and open ocean (figure not shown).

\subsection{Vertical Rain Rate Profiles. The TRMM PR has provided} vertical profiles of rainfall, which is very important for studying the vertical structure of rain corresponding to a particular rain rate. These profiles can be used to represent the rainfall accumulated within each layer. Here, vertical rain rate profiles from 2 to $16 \mathrm{~km}$ during JJA for all, stratiform, and convective rain are examined to understand the storm structures over the study area. The profiles are taken only for rain cases. Vertical profiles of rain rate over the coastal ocean and coastal mountains are investigated separately since echotop height is higher in the former and lower in the latter in both regions (Figure 6).

One common feature in the vertical rain rate profiles is that the rates over the coastal oceans are higher than over the mountains (up to approximately $5 \mathrm{~km}$ AMSL). However, the difference is greater over the WG than the MWC region. The difference tends to be smaller in the lower atmosphere; the maximum difference is observed at about $4 \mathrm{~km}$ AMSL. Over the coastal ocean of the MWC region, the lower part of the stratiform rain rate profile is nearly constant up to $5 \mathrm{~km}$, similar to the rain-rate profile observed in the central Himalayas. This result suggests a deeper layer of moisture in the respective region (the vertical profile of specific humidity revealed higher values over the central Himalayas and MWC regions) (Figure not shown). For convective rain, the rate decreases monotonically with height regardless of topography in both regions. In general, at elevations above $5 \mathrm{~km}$, rain rates in the MWC region are much greater than that in the WG, which indicates that the rain systems are much deeper in the MWC than in the WG. Biasutti et al. [35] also noted that the Bay of Bengal has higher conditional reflectivity at $6 \mathrm{~km}$ altitude than the WG region. Figure 7 shows an example of the vertical structure of conditional rain rates and is in good agreement with these features.

3.3. Atmospheric Conditions. Atmospheric stability is now examined because it gives important insights to understand the underlying mechanisms of South Asian summer precipitation. Climatological variables (temperature, moisture, and wind) that are available at both climatological and individual scales are used. Evaluating the vertical structure of equivalent potential temperature $\left(\theta_{e}\right)$ is an important meteorological variable to understand the atmospheric instability. The vertical structure of the circulation field during the summer monsoon climate, from JRA-25 reanalysis, is shown in Figure 8. Although the general patterns are remarkably similar between the two coastal regions, there are clear differences in horizontal wind direction and $\theta_{e}$ (Figures $8(a)$ and $8(b)$ ). Westerly wind is prominent over the WG region while the MWC regions are dominated by strong southwesterly winds. Over the WG region, the strong, moist westerly winds from the Arabian Sea strike the terrain perpendicularly. The difference in $\theta_{e}$ between the 600 and $925 \mathrm{hPa}$ pressure levels shows stronger atmospheric instability in the MWC region, and higher $\theta_{e}$ is observed there as well. The higher specific humidity $(16 \mathrm{~g} / \mathrm{kg}$ at $900 \mathrm{hPa})$ over the MWC compared with the WG $(14 \mathrm{~g} / \mathrm{kg}$ at $900 \mathrm{hPa})$ confirms that the higher $\theta_{e}$ over the MWC is due to a large amount of water vapor in the atmosphere. 


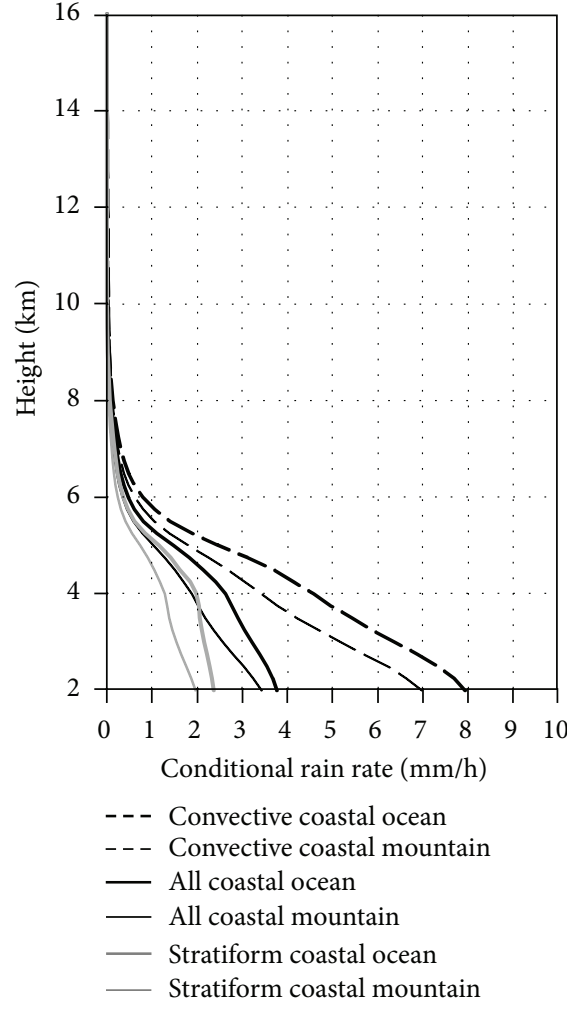

(a) WG

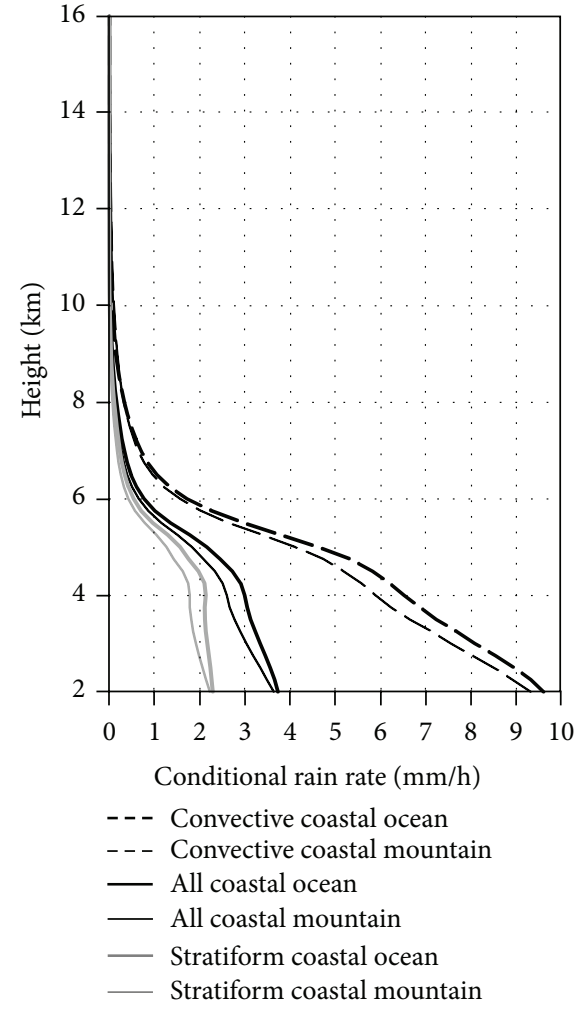

(b) MWC

Figure 6: Vertical profiles of conditional rain rates for the (a) WG and (b) MWC. See Figure 1 for locations.

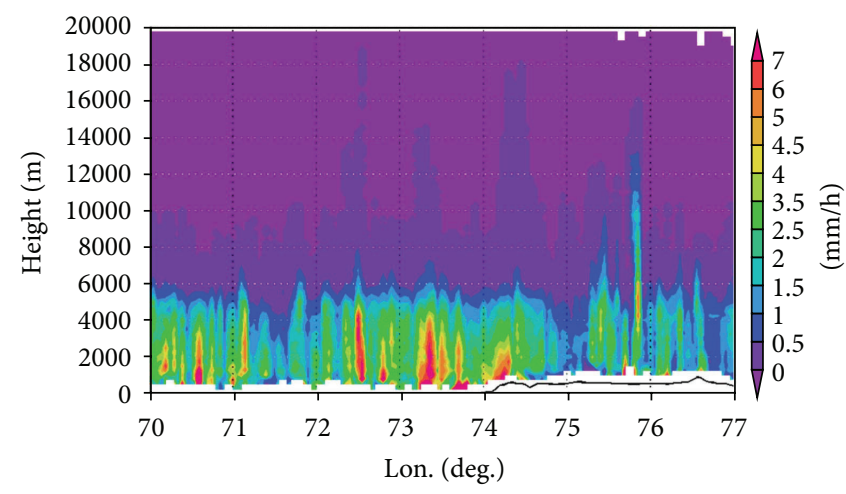

(a) WG $(15 \mathrm{~N})$

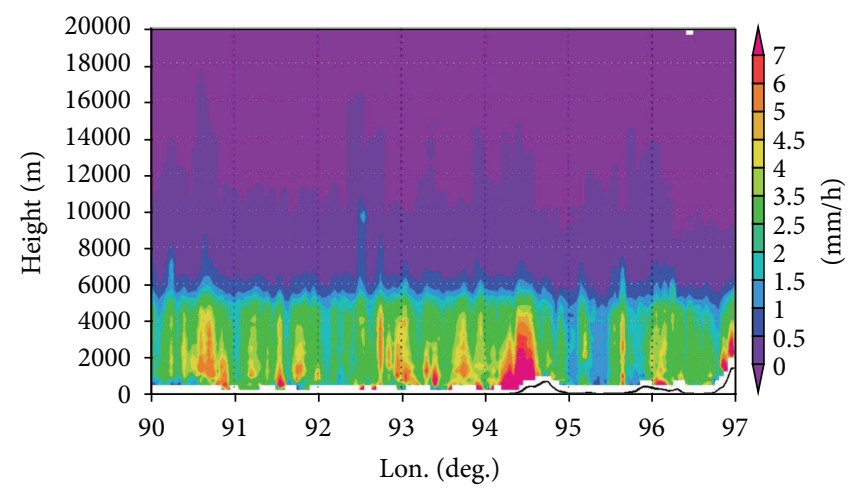

(b) MWC $(18.5 \mathrm{~N})$

Figure 7: Vertical rain rate cross sections in the 13-year period (1998-2010) for the WG at $15^{\circ} \mathrm{N}$ (a) and MWC at $18.5^{\circ} \mathrm{N}$ (b). Black lines represent east-west topography of the coastal mountain ranges. See Figure 1 for locations.

\section{Discussion and Conclusions}

In this study, 13 years (1998-2010) of summer monsoon (June-August) rainfall data were compiled at very high spatial resolution $\left(0.05^{\circ} \times 0.05^{\circ}\right)$ obtained from TRMM PR V6. The spatial distributions of precipitation characteristics over the western coastal mountainous areas of South Asia, with a specific focus on topographic effects, are characterized in terms of rain frequency, intensity, type, and vertical structure of rain rate. Atmospheric conditions are also analyzed in terms of equivalent potential temperature to determine the mechanisms involved in the development of spatially distinct precipitation systems.

A previous study showed the spatial correlation among topography, rain frequency, and intensity, which determines the position of the double rainfall band in the central Himalayan region [17]. Investigation in both coastal mountainous regions of south Asia also revealed a correlation between 


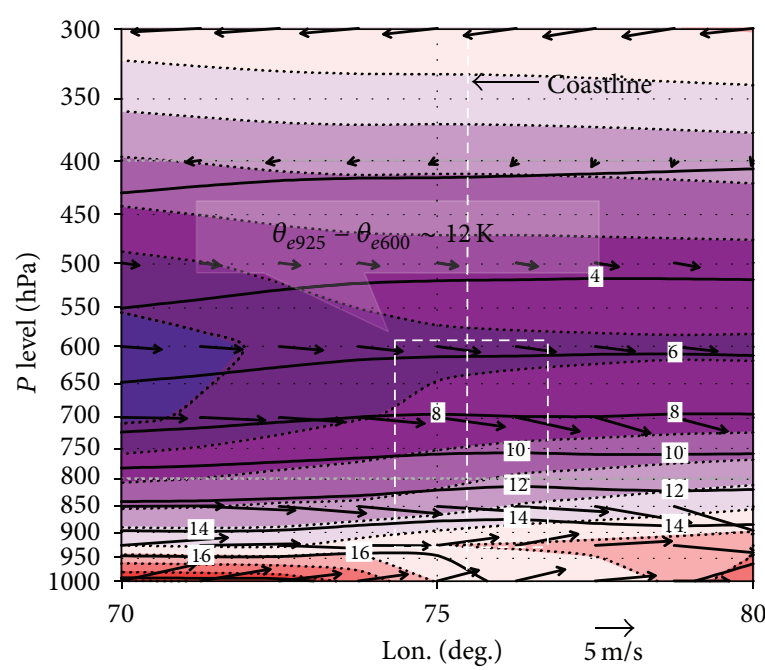

(a) WG

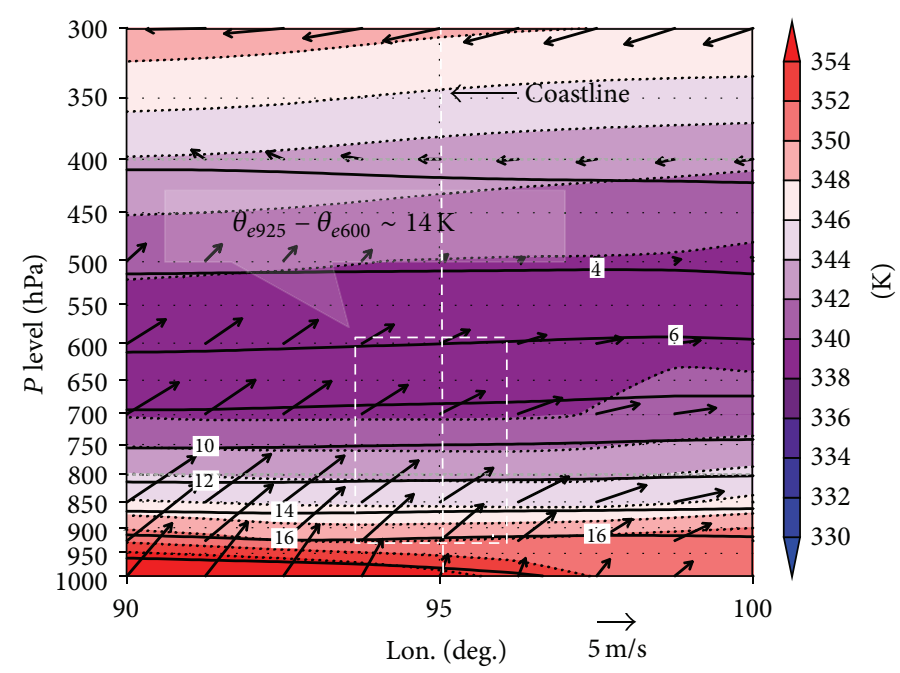

(b) MWC

FIGURE 8: Height-longitude sections of equivalent potential temperature (K, color shaded), horizontal wind vectors ( $\mathrm{m} / \mathrm{s}$, black arrows), and specific humidity (g/kg; contours) for the (a) WG at $15^{\circ} \mathrm{N}$ and (b) $\mathrm{MWC}$ at $18.5^{\circ} \mathrm{N}$. White dashed rectangles and line roughly represent the cross sections of the study areas and coastlines, respectively. See Figure 1 for locations.

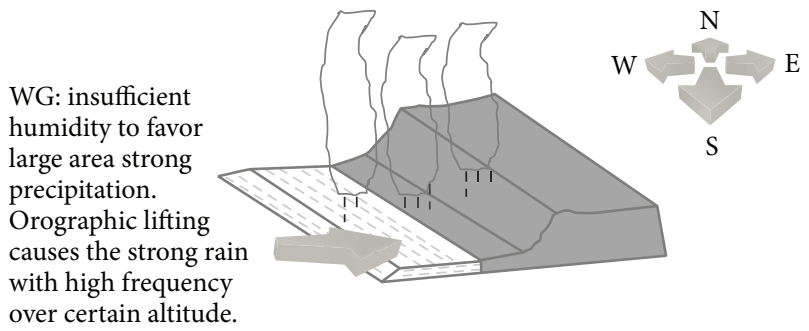

(a) Western Ghats (WG)

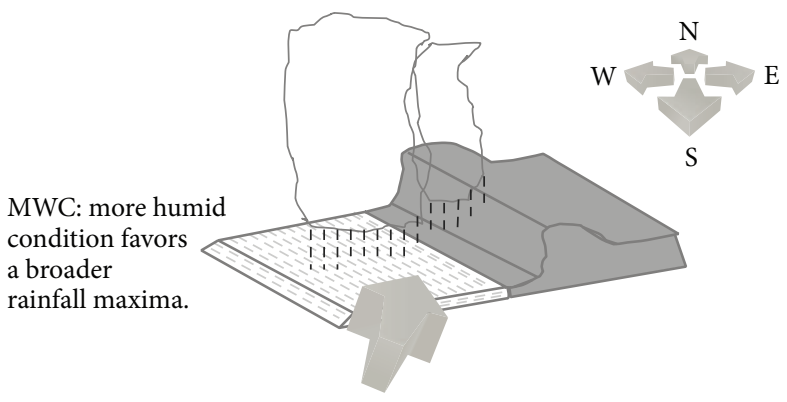

(b) Myanmar West Coast (MWC)

FIGURE 9: Schematic illustrations of the spatial patterns of precipitation for the (a) WG and (b) MWC.

terrain elevation and the location of rainfall maxima. However, the correlation varies greatly from place to place. A schematic of summer monsoon rainfall mechanisms in the study area is shown in Figure 9. Over the coastal regions, the heaviest precipitation zone locates primarily over the western slope of the coastal mountains and extends westward over the oceans. Primary factors determining the peak rainfall over the coastal mountains and ocean are rain frequency and intensity, respectively. A rainfall maximum that strongly increases in frequency as elevation increases is indicative of orographic anchoring. A weak signature in the diurnal cycle of small and medium systems in the coastal mountains of the WG and MWC, which play a dominant role in total rainfall over the WG and a significant role over the MWC [12], suggests that an orographic response to the prevailing lowlevel southwesterly monsoon flow is a key factor in addition to the land-ocean contrast. As the southwest monsoon impinges on the narrow coastal mountains of the west coasts of India and Myanmar, moisture-laden air is forced to rise and causes frequent convection on the upwind sides. In addition to the orographic lifting effect as a dynamic barrier to the prevailing winds, coastal mountains play an important role in a strong diurnal cycle of convection over the coastal ocean and surrounding lands due to diurnal thermal forcing [22]. Intense rainfall associated with taller storm-top heights over coastal oceans is more likely because of stronger morning convergence when the onshore progression of monsoon flow along the coast is slowed down by cooling over the continent.

There is a substantial difference in the precipitation mechanisms between the WG and MWC (Figures 9(a) and 9(b)). The systems in the WG region tend to be more convective compared to those in the MWC, although the storm-tops were much higher in the MWC regions. Romatschke and Houze Jr. [12] also identified that most systems in the WG region were small or medium, while systems in the MWC were mostly large in size. They further reported a great 
amount of shallow, nonextreme convection over the WG region, which does not develop into large systems. These differences could be related to the prevailing moisture and seasurface temperature conditions over these regions. The vertical structure of equivalent potential temperature confirms that the lower atmosphere over the MWC is more humid than that over the WG region. Insufficient moisture does not favor growth of large-scale precipitation systems over the WG region. However, strong, moist westerly winds from the Arabian Sea strike the terrain perpendicularly in a roughly north-south direction and rise vertically during the summer monsoon causing very heavy rainfall on the windward side. In contrast, sufficient humidity, high sea-surface temperatures and consequent orographic lifting help to generate large precipitation systems in the MWC regions. Several researchers have suggested that the Bay of Bengal depression favors the formation of mesoscale convective systems over the Bay of Bengal [38, 39].

In general, it is evident that mountains have a strong impact on the spatial distribution of precipitation characteristics. Specifically, steep mountains favor more-frequent nonextreme convection, which contribute a significant amount of rainfall over slopes in regions with large rain totals including the central Himalayas [17], Western Ghats, West Coast of Myanmar, and the eastern Andes [17]. Study of precipitation mechanisms over complex terrain-especially those based on rain frequency and conditional rain rate provided by the TRMM PR alone-is still incomplete. This study indicates some of the possible precipitation mechanisms that occur over the coastal mountains. Ultimately, advanced fine-scale models will be necessary to improve our understanding of the precipitation characteristics over complex mountainous terrain.

\section{Conflict of Interests}

The authors declare that there is no conflict of interests regarding the publication of this paper.

\section{Acknowledgments}

The authors would like to express their gratitude to members of the Laboratory of Satellite Meteorology and the Laboratory of Cloud and Precipitation at the Hydrospheric Atmospheric Research Center, Nagoya University, for their valuable suggestions and cooperation. The TRMM PR data were provided by Japan Aerospace Exploration Agency (JAXA). In addition, more meteorological data were obtained from the JRA-25 Long-term Reanalysis Cooperative Research Project conducted by the Japan Meteorological Agency (JMA) and the Central Research Institute of Electric Power Industry (CRIEPI).

\section{References}

[1] A. P. Barros and D. P. Lettenmaier, "Dynamic modeling of the spatial distribution of precipitation in remote mountainous areas," Monthly Weather Review, vol. 121, no. 4, pp. 1195-1214, 1993.
[2] P. Singh, K. S. Ramasastri, and N. Kumar, “Topographical influence on precipitation distribution in different ranges of western Himalayas," Nordic Hydrology, vol. 26, no. 4-5, pp. 259-284, 1995.

[3] N. Caine, "The rainfall intensity-duration control of shallow landslides and debris flows," Geografiska Annaler, Series A: Physical Geography, vol. 62, no. 1-2, pp. 23-27, 1980.

[4] J. R. Minder, D. R. Durran, G. H. Roe, and A. M. Anders, "The climatology of small-scale orographic precipitation over the olympic mountains: patterns and processes," Quarterly Journal of the Royal Meteorological Society, vol. 134, no. 633, pp. 817-839, 2008.

[5] K. Dairaku, S. Emori, and T. Oki, "Rainfall amount, intensity, duration, and frequency relationships in the Mae Chaem watershed in Southeast Asia," Journal of Hydrometeorology, vol. 5, no. 3, pp. 458-470, 2004.

[6] A. M. Anders, G. H. Roe, B. Hallet, D. R. Montgomery, N. J. Finnegan, and J. Putkonen, "Spatial patterns of precipitation and topography in the Himalaya," Special Paper of the Geological Society of America, vol. 398, pp. 39-53, 2006.

[7] B. Bookhagen and D. W. Burbank, "Topography, relief, and TRMM-derived rainfall variations along the Himalaya," Geophysical Research Letters, vol. 33, no. 8, Article ID L08405, 2006.

[8] A. P. Barros, S. Chiao, T. J. Lang, D. Burbank, and J. Putkonen, "From weather to climate-seasonal and interannual variability of storms and implications for erosion processes in the Himalaya," Special Paper of the Geological Society of America, vol. 398, pp. 17-38, 2006.

[9] B. C. Bhatt and K. Nakamura, "A climatological-dynamical analysis associated with precipitation around the southern part of the Himalayas," Journal of Geophysical Research D: Atmospheres, vol. 111, no. 2, Article ID D02115, 2006.

[10] S. W. Nesbitt and A. M. Anders, "Very high resolution precipitation climatologies from the Tropical Rainfall Measuring Mission precipitation radar," Geophysical Research Letters, vol. 36, no. 15, Article ID L15815, 2009.

[11] B. Bookhagen and M. R. Strecker, "Orographic barriers, highresolution TRMM rainfall, and relief variations along the eastern Andes," Geophysical Research Letters, vol. 35, no. 6, Article ID L06403, 2008.

[12] U. Romatschke and R. A. Houze Jr., "Characteristics of precipitating convective systems in the South Asian monsoon," Journal of Hydrometeorology, vol. 12, no. 1, pp. 3-26, 2011.

[13] U. Romatschke and R. A. Houze Jr., "Characteristics of precipitating convective systems in the premonsoon season of South Asia," Journal of Hydrometeorology, vol. 12, no. 2, pp. 157-180, 2011.

[14] R. A. Houze Jr., "Orographic effects on precipitating clouds," Reviews of Geophysics, vol. 50, no. 1, Article ID RG1001, 2012.

[15] A. P. Barros, M. Joshi, J. Putkonen, and D. W. Burbank, "A study of 1999 monsoon rainfall in a mountainous region in central Nepal using TRMM products and rain gauge observations," Geophysical Research Letters, vol. 27, no. 22, pp. 3683-3686, 2000.

[16] B. Bookhagen and D. W. Burbank, "Toward a complete Himalayan hydrological budget: spatiotemporal distribution of snowmelt and rainfall and their impact on river discharge," Journal of Geophysical Research F: Earth Surface, vol. 115, no. 3, Article ID F03019, 2010.

[17] D. Shrestha, P. Singh, and K. Nakamura, "Spatiotemporal variation of rainfall over the central Himalayan region revealed 
by TRMM precipitation radar," Journal of Geophysical Research D: Atmospheres, vol. 117, no. 22, Article ID D22106, 2012.

[18] O. N. Dhar and P. R. Rakhecha, "The effect of elevation on monsoon rainfall distribution in the central Himalayas," in Monsoon Dynamics, J. Lighthill and R. P. Pearce, Eds., pp. 253260, Cambridge University Press, Cambridge, UK, 1981.

[19] W. Buytaert, R. Celleri, P. Willems, B. D. Bièvreb, and G. Wyseurea, "Spatial and temporal rainfall variability in mountainous areas: a case study from the south Ecuadorian Andes," Journal of Hydrology, vol. 329, no. 3-4, pp. 413-421, 2006.

[20] C. Frei and C. Schär, "A precipitation climatology of the Alps from high-resolution rain-gauge observations," International Journal of Climatology, vol. 18, no. 8, pp. 873-900, 1998.

[21] S. Kumar, A. Hazra, and B. N. Goswami, "Role of interaction between dynamics, thermodynamics and cloud microphysics on summer monsoon precipitating clouds over the Myanmar Coast and the Western Ghats," Climate Dynamics, vol. 43, no. 3-4, pp. 911-924, 2014.

[22] S.-P. Xie, H. Xu, N. H. Saji, Y. Wang, and W. T. Liu, "Role of narrow mountains in large-scale organization of Asian Monsoon convection," Journal of Climate, vol. 19, no. 14, pp. 34203429, 2006.

[23] B. Venkatesh and M. K. Jose, "Identification of homogeneous rainfall regimes in parts of Western Ghats region of Karnataka," Journal of Earth System Science, vol. 116, no. 4, pp. 321-329, 2007.

[24] K. Dairaku, S. Emori, and T. Oki, "Observation and numerical experiments of Orographic precipitation in the Mae Chaem watershed in Southeast Asia," in Proceedings of the 6th International Study Confernce on GEWEX in Asia and GAME, GAME CD-ROM Publication No. 11, July 2004.

[25] E. T. Engman and D. M. Hershfield, Precipitation Climatology of the Sleepers River Watershed Near Danville, Vermont, United States Department of Agriculture, Agricultural Research Service, 1969.

[26] Z. Sokol and V. Bližňák, "Areal distribution and precipitationaltitude relationship of heavy short-term precipitation in the Czech Republic in the warm part of the year," Atmospheric Research, vol. 94, no. 4, pp. 652-662, 2009.

[27] C. Kummerow, W. Barnes, T. Kozu, J. Shiue, and J. Simpson, "The Tropical Rainfall Measuring Mission (TRMM) sensor package," Journal of Atmospheric and Oceanic Technology, vol. 15, no. 3, pp. 809-817, 1998.

[28] C. Kummerow, J. Simpson, O. Thiele et al., "The status of the tropical rainfall measuring mission (TRMM) after two years in orbit," Journal of Applied Meteorology, vol. 39, no. 12, pp. 19651982, 2000.

[29] S. Nair, G. Srinivasan, and R. Nemani, "Evaluation of multisatellite TRMM derived rainfall estimates over a western state of India," Journal of the Meteorological Society of Japan, vol. 87, no. 6, pp. 927-939, 2009.

[30] T. L. Bell and P. K. Kundu, "Dependence of satellite sampling error on monthly averaged rain rates: comparison of simple models and recent studies," Journal of Climate, vol. 13, no. 2, pp. 449-462, 2000.

[31] T. Iguchi, T. Kozu, R. Meneghini, J. Awaka, and K. I. Okamoto, "Rain-profiling algorithm for the TRMM precipitation radar," Journal of Applied Meteorology, vol. 39, no. 12, pp. 2038-2052, 2000.

[32] J. Awaka, T. Iguchi, H. Kumagai, and K. Okamoto, "Rain type classification algorithm for TRMM precipitation radar," in Proceedings of the IEEE International Geoscience and Remote
Sensing Symposium (IGARSS '97), pp. 1633-1635, IEEE, Singapore, August 1997.

[33] M. Steiner, R. A. Houze Jr., and S. E. Yuter, "Climatological characterization of three-dimensional storm structure from operational radar and rain gauge data," Journal of Applied Meteorology, vol. 34, no. 9, pp. 1978-2007, 1995.

[34] C. D. Hoyos and P. J. Webster, "The role of intraseasonal variability in the nature of Asian monsoon precipitation," Journal of Climate, vol. 20, no. 17, pp. 4402-4424, 2007.

[35] M. Biasutti, S. E. Yuter, C. D. Burleyson, and A. H. Sobel, "Very high resolution rainfall patterns measured by TRMM precipitation radar: seasonal and diurnal cycles," Climate Dynamics, vol. 39, no. 1-2, pp. 239-258, 2012.

[36] R. L. Grossman and D. R. Durran, "Interaction of low-level flow with the Western Ghat Mountains and offshore convection in the summer monsoon," Monthly Weather Review, vol. 112, no. 4, pp. 652-672, 1984.

[37] A. A. L. N. Sarma and B. Sivaram, "Spatiotemporal distribution of weekly hydroclimatic potentialities of IndiaJ-monsoon period," Indian Geophysical Union, vol. 15, pp. 9-24, 2011.

[38] R. A. Houze Jr., D. C. Wilton, and B. F. Smull, "Monsoon convection in the Himalayan region as seen by the TRMM precipitation radar," Quarterly Journal of the Royal Meteorological Society, vol. 133, no. 627, pp. 1389-1411, 2007.

[39] U. Romatschke, S. Medina, and R. A. Houze, "Regional, seasonal, and diurnal variations of extreme convection in the South Asian region," Journal of Climate, vol. 23, no. 2, pp. 419-439, 2010. 

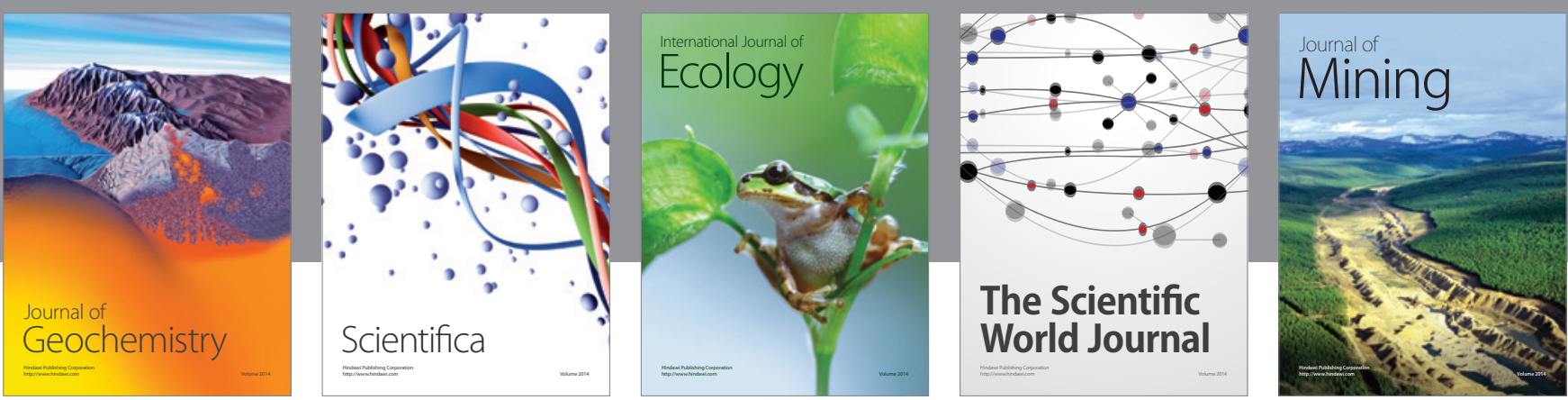

The Scientific World Journal
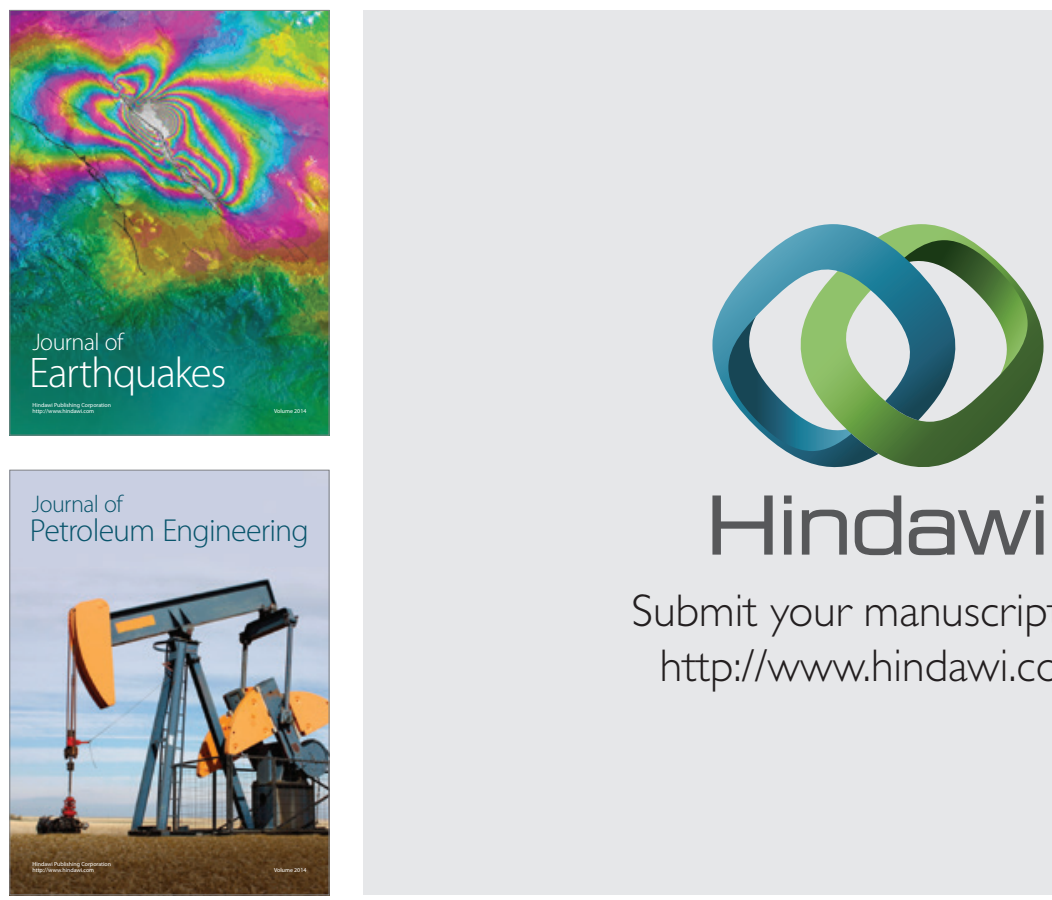

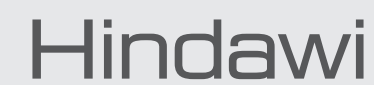

Submit your manuscripts at

http://www.hindawi.com
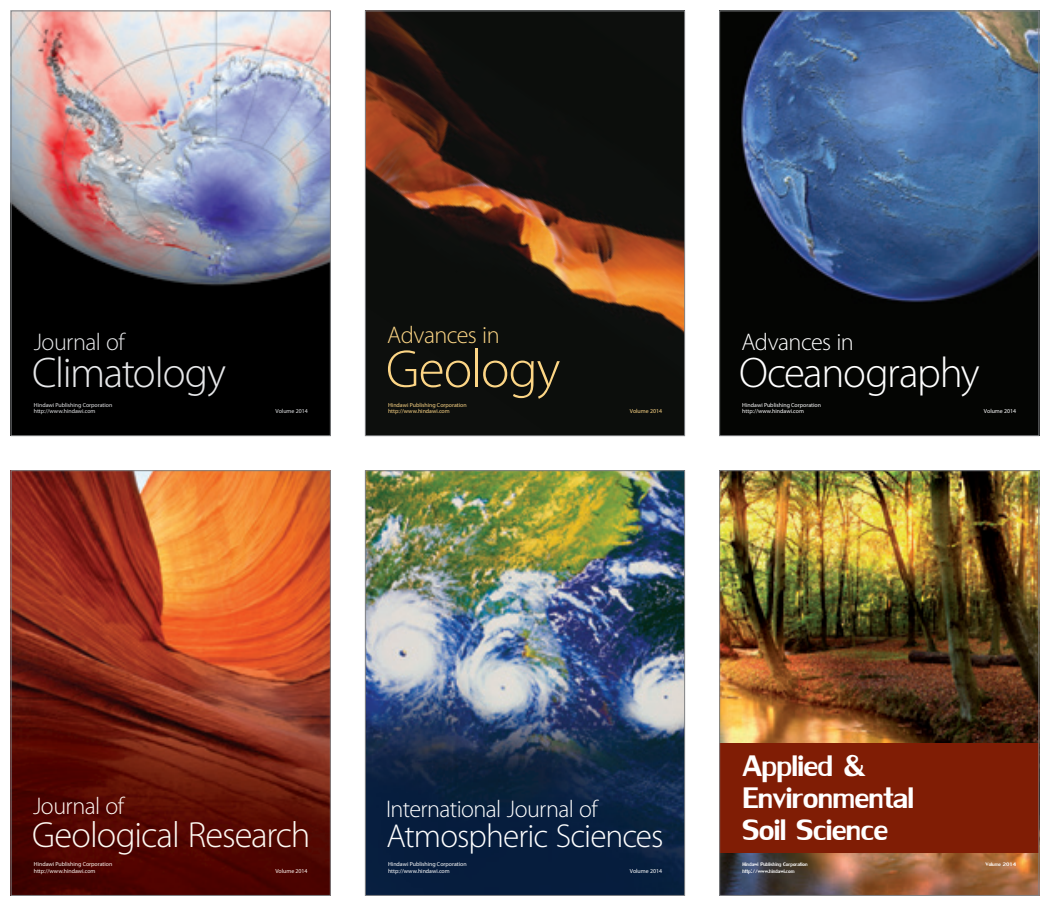
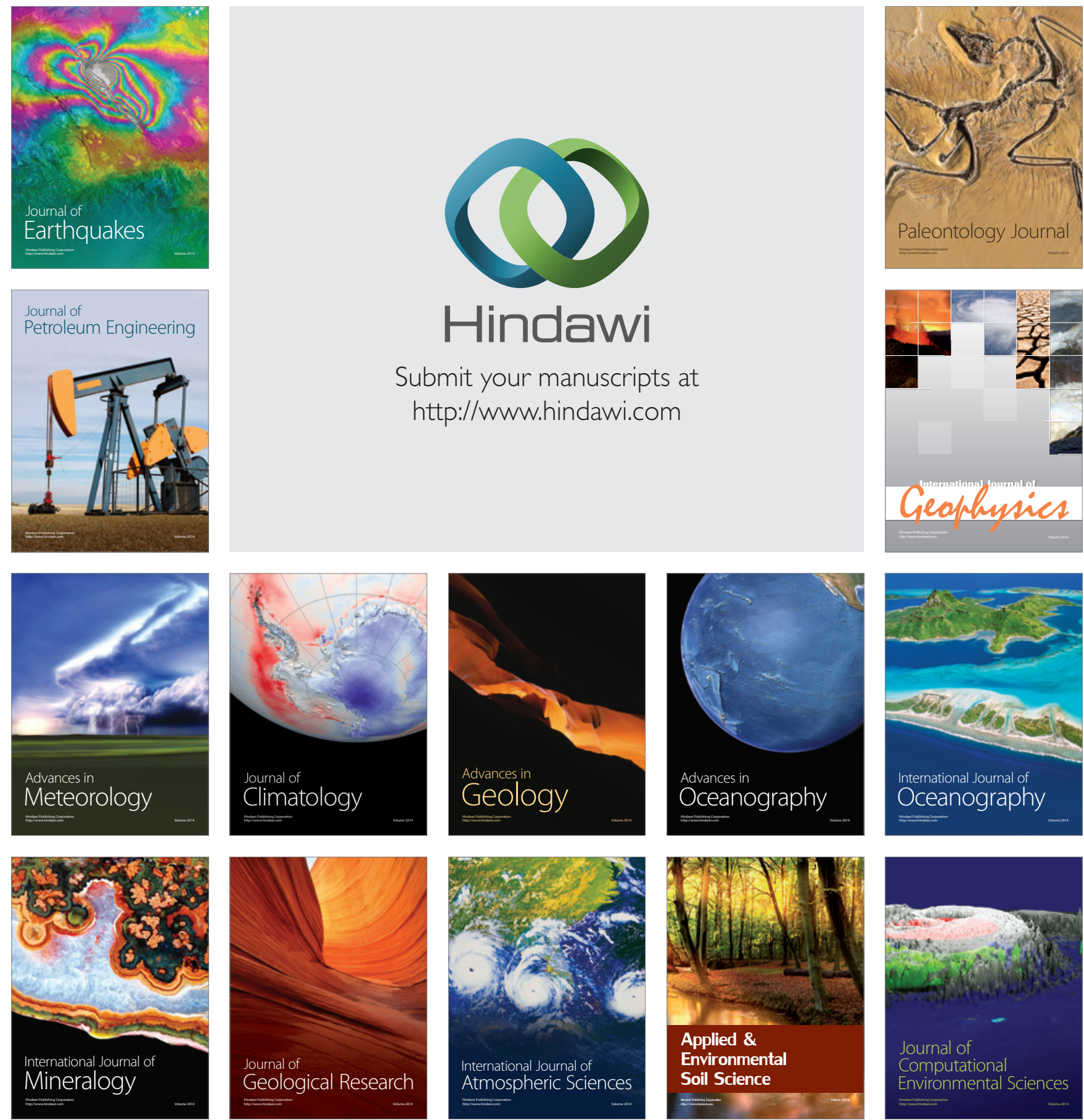